\title{
OHVIRA syndrome in 14-year-old girl
}

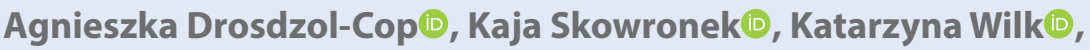 \\ Krzysztof Wilk@, Rafal Stojko@
}

Chair and Department of Gynecology, Obstetrics and Gynecological Oncology, Medical University of Silesia in Katowice, Poland

\section{INTRODUCTION}

Obstructed hemivagina and ipsilateral renal anomaly (OHVIRA) syndrome is an uncommon urogenital — congenital anomaly, characterized by the triad: uterine didelphys, obstructed hemivagina, unilateral renal agenesis. It is associated with abnormal development of the Mullerian and Wolffian ducts [1]. The syndrome appears at $<1 / 1000000$ girls.

Patients usually present the OHVIRA when adolescent, 1-2 years after menarche. Regularly reported symptoms are dysmenorrhea and pelvic pain [2,3]. Recommended treatment for the patients with this syndrome is a minimally invasive surgery [3].

\section{CASE REPORT}

Girl aged 14 was admitted to Chair and Department of Gynecology, Obstetrics and Gynecological Oncology in Katowice complaining about sever lower abdominal pain. During last two months pain level was increasing. The patient attained menarche at the age of 13. She experienced regular, but light menstrual cycles, and had a few episodes of a lower abdominal pain following her menses. Physical examination was unremarkable with normal secondary sexual characteristics. When the patient was six years old was diagnosed with an absent left kidney (Fig. 1).

Pelvic examination revealed a flexible, tender mass of $10 \mathrm{~cm}$ diameter. The pelvis ultrasonography revealed didelphys uterus, two uterine cavities and cervices. The right uterus was measured as $43 \times 23 \mathrm{~mm}$ and were displaced to the right side, endometrium thickness $-4.5 \mathrm{~mm}$. Left corpus of uterus and cervix were enlarged and filled with blood (hematometra) with the accumulation of blood in the vagina (hematocolpos), measured $80 \times 60 \mathrm{~mm}$ (Fig. 2). Both ovaries were normal. Left kidney was absent in its anatomical location. Transverse vaginal septum was sized $5.5 \mathrm{~mm}$.

The patient was treated with hemivaginal septal resection, resulting in an outflow of old menstrual blood. The incision made during the procedure should have appropriate size to prevent it from regrowing. It is extremely important to take care of the patency between the lumen of the right and left vagina for allowing the menstrual blood to outflow. The incision was marsupialized with single sutures. A foley catheter was placed into the left vagina to keep the hole created (Fig. 3). During subsequent visits, the dimensions of the left cavity and the cervix decreased due to the emptying of residual blood from these structures. The opening remained open, vaginal dilators were used by the patient with full acceptance and the pain was significantly reduced.

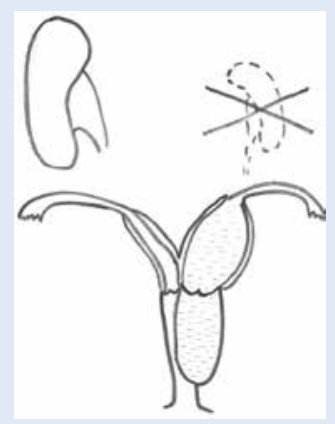

Figure 1. Schematic representation of OHVIRA syndrome [4]

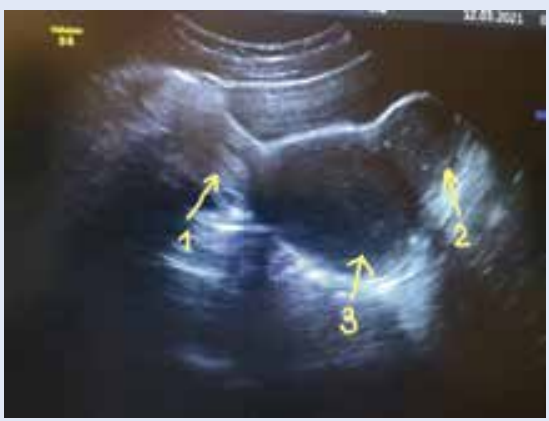

Figure 2. Ultrasonography image: uterus didelphys (right uterus - 1; left uterus - 2) and hematocolpos (3)

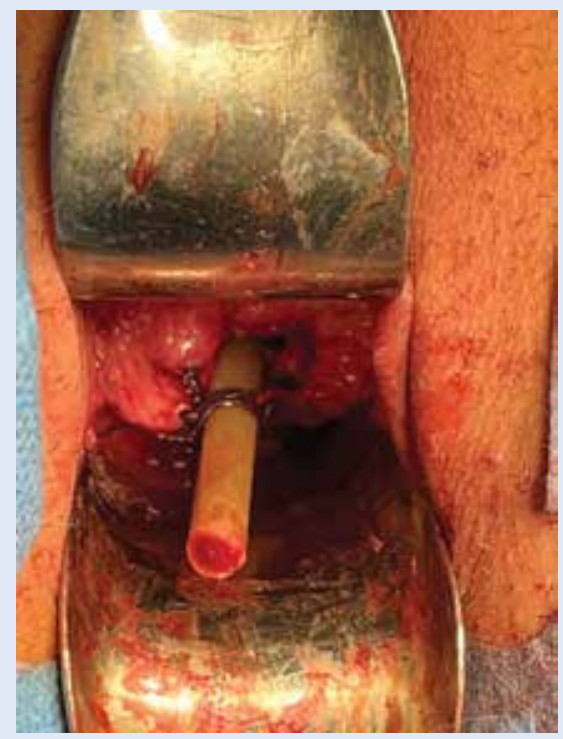

Figure 3. Vaginal operation: a foley catheter placed into the left vagina

Corresponding author:

Kaja Skowronek,

Chair and Department of Gynecology, Obstetrics and Gynecological Oncology, Medical University of Silesia, 87 Markiefki St, 40-211 Katowice, Poland phone: +4832 208 8730; e-mail: skowronek.kaja@gmail.com

This article is available in open access under Creative Common Attribution-Non-Commercial-No Derivatives 4.0 International (CC BY-NC-ND 4.0) license, allowing to download articles and share them with others as long as they credit the authors and the publisher, but without permission to change them in any way or use them commercially. 


\section{CONCLUSION}

Pathogenesis of this syndrome is associated with development of the Mullerian and Wolffian structures. The most frequently clinical symptom reported by patients is cyclic abdominal pain which most often occurs shortly after the menarche [1]. The diagnostic methods of this syndrome are pelvic ultrasound and imaging tests; however, the golden standard is magnetic resonance imaging (MRI) [4]. The septum removal procedure should be performed with appropriate care to prevent excessive bleeding, damage to the bladder, rectum and cervix. If the patient was not treated properly it may result with retrograde tubal reflux, endometriosis and fertility problems [2]. After surgery, adolescent patients should undergo regular follow-up visits in order to prevent an adhesion formation recurrence after vaginal septum resection.

\section{Conflicts of interest}

The authors declare no conflict of interest.

\section{REFERENCES}

1. Nigam A, Raghunandan C, Yadav R, et al. OHVIRA syndrome: rare cause of chronic vaginal discharge in an unmarried female. Congenit Anom (Kyoto). 2011; 51(3): 153-155, doi: 10.1111/j.1741-4520.2010.00293.x, indexed in Pubmed: 20726998.

2. Sidhu HS, Madaan PK. Herlyn-Werner-Wunderlich syndrome in a multiparous female. BJR Case Rep. 2021; 7(1): 20200132, doi: 10.1259/bjrcr.20200132, indexed in Pubmed: 33614122.

3. Kudela G, Bialka A, Koszutski T, et al. Use of holmium laser for OHVIRA syndrome treatment. Ginekol Pol. 2019; 90(5):289-290, doi: 10.5603/GP.a2019.0055, indexed in Pubmed: 31111461.

4. Han JH, Lee YS, Im YJ, et al. Clinical Implications of Obstructed Hemivagina and Ipsilateral Renal Anomaly (OHVIRA) Syndrome in the Prepubertal Age Group. PLoS One. 2016; 11(11): e0166776, doi: 10.1371/journal.pone.0166776, indexed in Pubmed: 27861623. 